\title{
DETEKSI DAN ISOLASI KESALAHAN BERBASIS PD DESCRIPTOR OBSERVER MENGGUNAKAN HUKUM CTC PADA ROBOT MANIPULATOR
}

\author{
Titi Andriani ${ }^{1}$, Katherin Indriawati ${ }^{2}$, Rusdhianto Effendi A.K. ${ }^{3}$ \\ ${ }^{1}$ Institut Teknologi Sepuluh Nopember, Surabaya, ${ }^{2}$ Institut Teknologi Sepuluh Nopember, Surabaya \\ ${ }^{3}$ Institut Teknologi Sepuluh Nopember, Surabaya \\ titin.rahman@gmail.com
}

\begin{abstract}
Abstrak
Secara umum robot dapat meningkatkan produktivitas produksi yang memberikan keuntungan lebih. Dalam bidang industri misalnya, penggunaan robot ditujukan untuk menggantikan peran manusia dalam melaksanakan tugas-tugas yang membutuhkan tenaga besar dan ketelitian tinggi. Terjadinya kesalahan sensor pada robot dapat menyebabkan penurunan hasil produksi. Untuk keperluan proses monitoring, deteksi dan isolasi kesalahan (Fault Detection and Isolation/FDI) memainkan peranan penting dalam memberikan informasi tentang kesalahan sistem untuk memungkinkan rekonfigurasi yang tepat. Untuk FDI yang berbasis residual, tugas yang sangat penting adalah teknik desain observer yang mampu mengestimasi sinyal kesalahan pada pengukuran sehingga miss detection dan false alarm dapat dihindari. Selain itu, harus dipilih metode kontrol yang tepat yang mampu mengatasi ketidaklinieran pada robot manipulator.

Computed Torque Controller (CTC) adalah kontroler nonlinier yang telah digunakan secara luas pada kontrol robot manipulator. Kontrol ini didasarkan pada linearisasi umpan balik dan perhitungan torsi yang diperlukan lengan robot menggunakan hukum kontrol umpan balik nonlinear. Untuk sistem dengan noise pengukuran, observer Proportional Derivative (PD) dikonstruksi untuk mengestimasi residual noise pengukuran. Gain proportional dipilih untuk memastikan kestabilan dinamika error yang diestimasi dan gain derivative dipilih untuk mengurangi amplifikasi noise. Observer PD selanjutnya diaplikasikan pada mekanisme deteksi dan isolasi kesalahan sensor robot manipulator.

Dengan menerapkan CTC pada robot manipulator, didapatkan sinyal kontrol umpan balik linier yang menjadi input bagi modified PD descriptor observer. Transformasi pemodelan robot manipulator ke dalam sistem augmented descriptor sehingga diperoleh formulasi desain observer yang baru yang mampu mengestimasi kesalahan pengukuran dan dapat diterapkan pada mekanisme FDI untuk memberikan sinyal alarm yang sesuai dengan sinyal kesalahan yang diinputkan pada pengukuran yang disimulasikan.
\end{abstract}

Kata Kunci : Robot manipulator; Deteksi kesalahan; CTC; Noise Pengukuran; Observer PD

\section{PENDAHULUAN}

Secara umum, robot dapat meningkatkan produktivitas produksi secara efisien yang memberikan keuntungan lebih. dalam bidang industri missalnya, penggunaan robot ditujukan untuk menggantikan peran manusia dalam melaksanakan tugas-tugas yang membutuhkan tenaga yang besar dan memerlukan ketelitian yang tinggi. Robot juga dapat digunakan secara terus menerus tanpa merasakan adanya kebosanan dalam melakukan pemroduksian dan dapat juga digunakan pada lingkungan yang sangat berbahaya misalnya dalam industri nuklir.
Untuk menjaga keberlangsungan produksi, proses monitoring sangatlah dibutuhkan untuk memastikan keefek-tifan proses dan keandalan sistem secara keseluruhan. Untuk keperluan proses monitoring tersebut, deteksi dan isolasi kesalahan (Fault Detection and Isolation/ FDI) memainkan peranan penting dalam memberikan informasi tentang kesalahan dalam sistem untuk memungkinkan rekonfigurasi yang tepat. Fungsi utama dari deteksi dan isolasi kesalahan adalah untuk mendeteksi kesalahan dan untuk menemukan lokasi terjadinya sehingga tindakan korektif dapat dilakukan untuk 
menghilangkan atau meminimalkan dampak pada kinerja sistem secara keseluruhan.

Studi dan metode FDI dapat terbagi dalam dua kelompok utama: metode berbasis data dan metode berbasis model. Metode FDI berbasis data didasarkan pada pengolahan sinyal masukan dan keluaran sistem. Sedangkan metode FDI berbasis model didasarkan pada pemo-delan sistem dan mengolah perbedaan antara sinyal model dengan sinyal sistem yang sesungguhnya yang disebut residual. Metode FDI berbasis model dapat ditemukan dalam (Nie, C., 2012, dan Zhang, K., 2011).

Pendekatan yang berbeda telah dikembangkan dalam FDI, salah satunya adalah FDI berbasis observer. Desain observer untuk sistem yang mengan-dung faktor uncertainties telah menjadi topik penelitian yang penting selama 20 tahun terakhir. Namun, sebagian besar pendekatan yang ada tidak terlalu cocok untuk penanganan noise pengukuran karena noise pengukuran ini diperkuat oleh adanya gain matriks observer ketika observer konvensional digunakan.

Pada penelitian yang dilakukan oleh (Zhiwei Gao dan Hong Wang, 2005), dikembangkan modified $P D$ descriptor observer untuk sistem yang mengandung noise pengukuran. Gain derivative dipilih untuk mereduksi efek dari noise output dan gain Proportional dipilih untuk menjamin stabilitas dari dinamika error. Teknik desain tersebut mampu mencapai estimasi state sistem dan noise pengukuran (termasuk ketidakpastian input) secara simultan. Akan tetapi modified PD descriptor observer tersebut hanya ditrapkan pada plant linear multivariabel. Sehingga kami mengusulkan penerepan PD descriptor observer ini pada plant nonlinear.

Secara umum, penelitian ini bertujuan untuk membangun sistem deteksi dan isolasi berbasis modified PD descriptor observer untuk mendeteksi kesalahan sensor pada robot manipulator planar 2Link. Dengan menerapkan metode deteksi dan isolasi kesalahan ini, diharapkan keandalan sistem pengaturan posisi pada robot manipulator planar 2-Link dapat ditingkatkan. Capaian tujuan tersebut secara langsung akan memberikan kontribusi bagi peningkatan produktivitas produksi yang memberikan keuntungan lebih dalam bidang industri.

\section{METODE PENELITIAN}

Penelitian ini dilakukan dalam beberapa tahap. Pertama, memodelkan robot manipulator robot manipulator yang akurat yang dapat menggambarkan perilaku sistem secara keseluruhan. Kedua, perancangan kontroler menggunakan hukum Computed Torque Controller dengan melakukan pemilihan gain PID yang sesuai. Ketiga, mendapatkan modified PD descriptor observer untuk mendeteksi kesalahan yang terjadi pada beberapa sensor.

\section{Pemodelan Robot Manipulato}

Secara umum, persamaan dinamika manipulator dituliskan sebagai (1),

$$
M(q) \ddot{q}+V(q, \dot{q})+G(q)+\tau_{d}=\tau
$$

Dengan $q(t), \dot{q}(t)$, and $\ddot{q}(t) \in R^{n}$ posisi sudut, kecepatan dan percepatan pada masing-masing link, $M(q) \in R^{n \times n}$ matriks inersia definit positif, $V(q, \dot{q}) \in R^{n}$ vektor Coriolis dan sentripetal, $G(q) \in R^{n}$ vektor grafitasi dan $\tau \in R^{n}$ vektor torsi yang disediakan ke joint. Jika faktor nonlinear pada (1) memiliki percepatan sudut yang diekspresikan sebagai

$N(q, \dot{q})=V(q, \dot{q})+G(q)$, maka $(1)$

menjadi (2):

$$
M(q) \ddot{q}+N(q, \dot{q})+\tau_{d}=\tau
$$

Persamaan dinamika robot manipulator 2-link pada Gambar 1. dapat dituliskan pada Persamaan (3), 


$$
\begin{aligned}
& {\left[\begin{array}{cc}
\left(m_{1}+m_{2}\right) a_{1}^{2}+m_{2} a_{2}^{2}+2 m_{2} a_{1} a_{2} \cos \theta_{2} & m_{2} a_{2}^{2}+m_{2} a_{1} a_{2} \cos \theta_{2} \\
m_{2} a_{2}^{2}+m_{2} a_{1} a_{2} \cos \theta_{2} & m_{2} a_{2}^{2}
\end{array}\right]\left[\begin{array}{l}
\ddot{\theta}_{1} \\
\ddot{\theta}_{2}
\end{array}\right]+} \\
& {\left[\begin{array}{c}
-m_{2} a_{1} a_{2}\left(2 \dot{\theta}_{1} \dot{\theta}_{2}+\dot{\theta}_{2}^{2} \sin \dot{\theta}_{2}\right. \\
m_{2} a_{1} a_{2} \dot{\theta}_{1}^{2} \sin \theta_{2}
\end{array}\right]+\left[\begin{array}{c}
\left(m_{1}+m_{2}\right) g a_{1} \cos \theta_{1}+m_{2} g a_{2} \cos \left(\theta_{1}+\theta_{2}\right) \\
m_{2} g a_{2} \cos \left(\theta_{1}+\theta_{2}\right)
\end{array}\right]-\left[\begin{array}{l}
\tau_{1} \\
\tau_{2}
\end{array}\right]}
\end{aligned}
$$

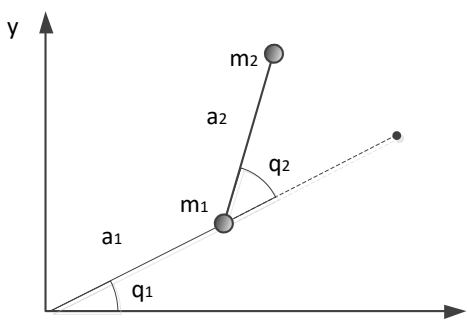

\section{Gambar 1. Robot Manipulator Planăr 2-Link [7]}

\section{Computed Torque Controller}

Computed Torque Controller adalah sebuah aplikasi khusus feedback linearization sistem nonlinear yang telah mendapatkan popularitas dalam teori sistem modern (Piltan, F., dkk, 2012, dan Lewis, F. L., dkk, 2006).

Untuk memastikan trajektori tracking dengan variabel joint, error tracking didefinisikan sebagai,

$$
e(t)=q_{d}(t)-q(t)
$$

Untuk menunjukan akibat dari torsi input $\tau(t)$ pada error tracking, didefinisikan juga

$$
\begin{aligned}
& \dot{e}=\dot{q}_{d}-\dot{q} \\
& \ddot{e}=\ddot{q}_{d}-\ddot{q}
\end{aligned}
$$

Penyelesaian untuk $\ddot{q}$ pada Persamaan (2) dan disubstitusi ke dalam (5)

$$
\ddot{e}=\ddot{q}_{d}+M^{-1}\left(N+\tau_{d}-\tau\right)
$$

Didefinisikan fungsi input kontrol

$$
u=\ddot{q}_{d}+M^{-1}(N-\tau)
$$

dan fungsi gangguan

$$
\omega=M^{-1} \tau_{d}
$$

Didefinisikan juga suatu state $x(t) \epsilon R^{2 n}$ dengan

$$
x=\left[\begin{array}{l}
e \\
\dot{e}
\end{array}\right]
$$

dan dituliskan dinamika error tracking sebagai

$$
\frac{d}{d t}\left[\begin{array}{l}
e \\
\dot{e}
\end{array}\right]=\left[\begin{array}{ll}
0 & I \\
0 & 0
\end{array}\right]\left[\begin{array}{l}
e \\
\dot{e}
\end{array}\right]+\left[\begin{array}{l}
0 \\
I
\end{array}\right] u+\left[\begin{array}{l}
0 \\
I
\end{array}\right] \omega
$$

Transformasi linearisasi umpan balik pada Persamaan (7) dapat dibalik untuk menghasilkan

$$
\tau=M\left(\ddot{q}_{d}-u\right)+N
$$

Persamaan (11) disebut sebagai hukum computed-torque controller. Tidak terdapat informasi state-space dalam Persamaan (1), (2) dan Persamaan (4) hingga (10). Oleh karena itu, jika dipilih suatu kontrol $u(t)$ yang menstabilkan Persamaan (10) sehingga $e(t)$ menuju nol, maka input kontrol nonlinier yang diberikan oleh $\tau(t)$ pada Persamaan (11) akan menyebabkan lengan robot pada Persamaan (1) akan mengikuti trajektori. Substitusi (11) ke dalam (2) akan menghasilkan,

$$
M \ddot{q}+N+\tau_{d}=M\left(\ddot{q}_{d}-u\right)+N
$$

Atau

$$
\ddot{e}=u+M^{-1} \tau_{d}
$$

\section{Modified PD descriptor observer}


Salah satu metode FDI adalah FDI berbasis observer. Observer adalah suatu algoritma yang bertujuan untuk mengestimasi state sistem berdasarkan model sistem. Sinyal dari model matematika sistem dan sinyal dari observer dibandingkan, perbedaan antara keduanya disebut residual. Pada kondisi bebas kesalahan, nilai residual akan sama dengan nol, dan sebaliknya (Alwi, H., 2011, dan Noura, H., dkk, 2009).

Descriptor observer adalah observer yang mendeskripsikan sistem dalam bentuk state space dengan menggunakan parameter-parameter sebagai berikut (Gao dan Wang, 2005),

$$
\begin{aligned}
& \dot{x}=A x+B u \\
& y=C x
\end{aligned}
$$

Model matematis dari observer sama seperti model matematis pada sistem atau plant dengan ditambahkan dengan gain observer menjadi persamaan berikut,

$$
\begin{aligned}
& \dot{\tilde{x}} A \tilde{x}+B u+K_{e}(y-\tilde{y}) \\
& \tilde{y}=C \tilde{x}
\end{aligned}
$$

Dengan memasukkan $y$ pada (15) dan $\hat{y}$ pada (16) ke dalam (16) diperoleh,

$$
\begin{aligned}
& \dot{\tilde{x}}=A \tilde{x}+B u+K(y-C \tilde{x}) \\
& \dot{\tilde{x}}=\left(A-K_{e} C\right) \tilde{x}+B u+K_{e} C x
\end{aligned}
$$

Untuk menentukan persamaan observer error, Persamaan (19) dikurangi dengan Persamaan (14) berikut,

$$
\begin{aligned}
& \dot{x}-\dot{\tilde{x}}=A x-A \tilde{x}-K_{e}(C x-C \tilde{x}) \\
& \dot{x}-\dot{\tilde{x}}=\left(A-K_{e} C\right)(x-\tilde{x})
\end{aligned}
$$

Jika model matematis telah sempurna, maka $x$ estimate akan sama dengan state sistem $(x)$. Akan tetapi, seringkali terjadi kesalahan pada model, sehingga akan menimbulkan error atau perbedaan antara $x$ dan $x$ estimate $(\tilde{x})$ yang dapat dirumuskan sebagai berikut.

$$
\begin{aligned}
& e=x-\tilde{x} \\
& \dot{e}=\left(A-K_{e} C\right) e
\end{aligned}
$$

Observer yang digunakan untuk mengestimasi keadaan sistem dan kesalahan pada hasil pengukuran dengan parameter proportional dan derivative disebut modified PD descriptor observer. Dengan adanya kesalahan pada hasil pengukuran, maka persamaan sistem dalam bentuk state space menjadi,

$$
\begin{aligned}
& \dot{x}(t)=A x(t)+B u(t) \\
& y(t)=C x(t)+\omega(t)
\end{aligned}
$$

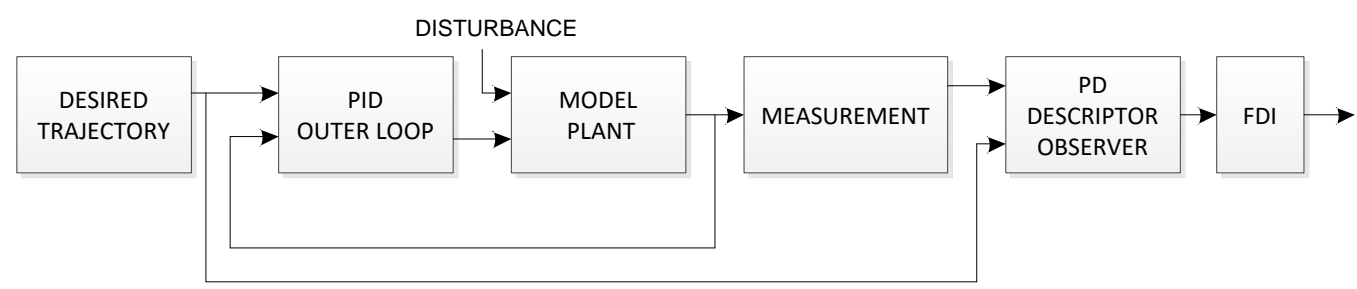

\section{Gambar 2. Blok Diagram Perancangan Sistem FDI berbasis PD Descriptor Observer}

Persamaan sistem dalam bentuk state space kemudian ditambahkan dengan matriks $\bar{E}$ untuk menunjukkan posisi sistem ketika terjadi kesalahan pada hasil pengukuran dan $\bar{N}$ sebagai matriks dari $\omega$, sehingga didapatkan persamaan augmented descriptor sebagai berikut. 
$\bar{E} \dot{\bar{x}}(t)=\bar{A} \bar{x}(t)+\bar{B} u(t)+\bar{N} \omega(t)$

$y(t)=\overline{C_{o}} \bar{x}(t)+\omega(t)=\bar{C} \bar{x}(t)$

Untuk menyusun modified $P D$ descriptor observer dengan kesalahan pada hasil pengukuran digunakan pendefinisian pada matriks-matriks berikut.

$$
\begin{aligned}
& \bar{B}=\left[\begin{array}{l}
B \\
0
\end{array}\right], \quad \bar{N}=\left[\begin{array}{l}
0 \\
I_{p}
\end{array}\right], \quad \bar{E}=\left[\begin{array}{cc}
I_{n} & 0 \\
0 & 0
\end{array}\right] \\
& \bar{C}=\left[\begin{array}{ll}
C & I_{p}
\end{array}\right], \quad \overline{C_{o}}=\left[\begin{array}{ll}
C & 0
\end{array}\right], \quad \bar{A}=\left[\begin{array}{cc}
A & 0 \\
0 & -I_{p}
\end{array}\right]
\end{aligned}
$$

Sedangkan persamaan yang digunakan untuk merancang modified PD descriptor observer adalah

$$
\begin{aligned}
& (\bar{E}+\bar{L} \bar{C}) \dot{\xi}(t)=\left(\bar{A}-\bar{N} \overline{C_{o}}-\bar{K} \bar{C}\right) \xi(t)+\bar{B} u(t) \\
& \hat{\bar{x}}(t)=\xi(t)+(\bar{E}+\bar{L} \bar{C})^{-1} \bar{L} y(t)
\end{aligned}
$$

Untuk mendapatkan gain proportional pada modified PD descriptor observer yaitu nilai $\bar{K}$ dicari dengan menggunakan command PLACE pada program MATLAB. Sedangkan untuk mendapatkan gain derivative pada

modified PD descriptor observer yaitu nilai $\bar{L}$ didefinisikan dari matriks berikut.

$$
\bar{L}=\left[\begin{array}{l}
L_{1} \\
L_{2}
\end{array}\right]
$$

Selanjutnya, perancangan sistem secara keseluruhan terdiri atas beberapa bagian seperti yang ditunjukkan pada Gambar 2.

\section{HASIL PENELITIAN DAN PEMBAHASAN}

PID Computed Torque Controller telah diuji dengan referensi sinyal sinusoidal. Pada simulasi ini, joint pertama dan kedua digerakkan dari posisi home ke posisi akhir dengan gangguan pada detik ke 10 sebesar $10 \mathrm{Nm}$ dan $5 \mathrm{Nm}$ untuk masing-masing joint. Untuk menguji error tracking, dipilih trajektory untuk kedua lengan robot sebagai berikut,

$$
\begin{array}{ll}
q_{d_{1}}=g_{1} \sin (2 \pi t / T), & q_{d_{2}}=g_{2} \cos (2 \pi t / T), \\
\dot{q}_{d_{1}}=g_{1}(2 \pi t / T) \cos (2 \pi t / T), & \dot{q}_{d_{2}}=-g_{2}(2 \pi t / T) \sin (2 \pi t / T) \\
\ddot{q}_{d_{1}}=-g_{1}(2 \pi t / T)^{2} \sin (2 \pi t / T), & \ddot{q}_{d_{2}}=-g_{2}(2 \pi t / T)^{2} \cos (2 \pi t / T)
\end{array}
$$

Gain PID ditentukan dengan pemilihan konstanta waktu sistem loop tertutup sebesar 0.1 detik. Sehingga diperoleh,

$$
\begin{aligned}
& \omega_{n}=10 \\
& K_{p}=2 \xi \omega_{n}^{2}+\omega_{n}{ }^{2}=210, \\
& K_{v}=2 \xi \omega_{n}+\omega_{n}=20, \\
& K_{i}=\omega_{n}{ }^{3}=1000
\end{aligned}
$$

Dengan,

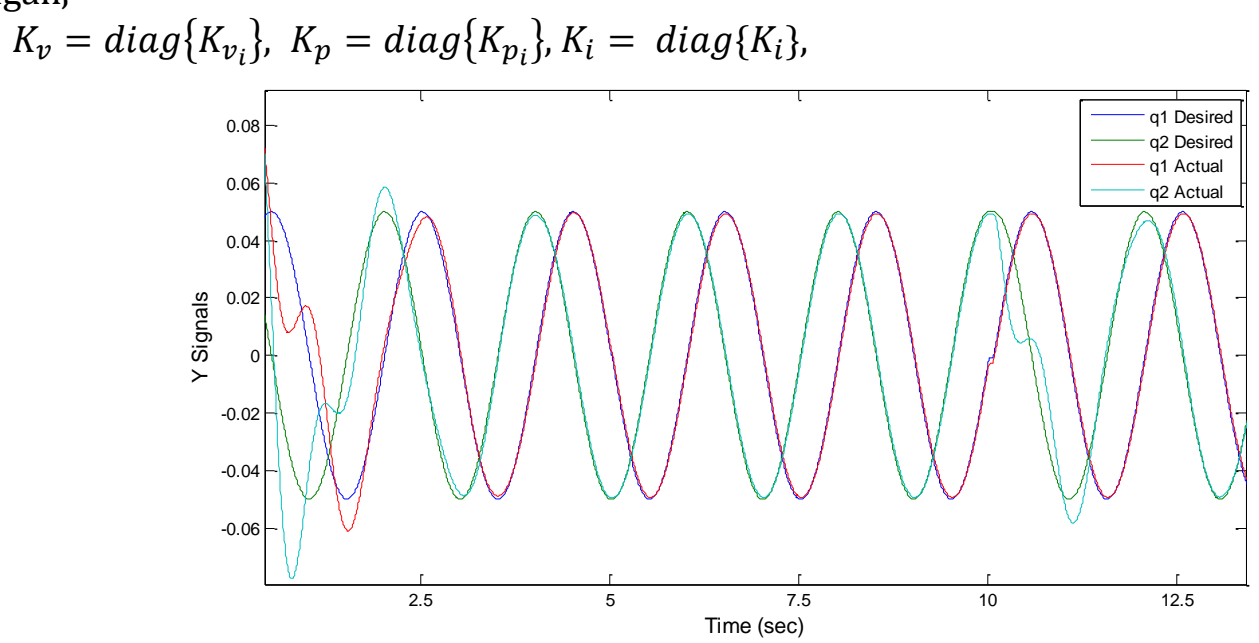

Gambar 3. PID CTC Error Tracking dengan Gangguan 
Efek dari torsi gangguan yang diberikan pada sistem terlihat pada Gambar 3. $q_{1}$ aktual dan $q_{1}$ aktual mengalami penyimpangan. Akan tetapi, pemilihan gain kontroler PD mampu membawa sistem kembali mengikuti trajectory selama tidak lebih dari 1 detik.

Selanjutnya, pengujian modified $P D$ descriptor observer dilakukan dengan memilih gain Proportional Observer $\bar{K}$ yang diperoleh dengan mendefinisian $K^{*}=$ place (Abar',Cbar',pole), di mana $\bar{K}=$ $\left(K^{*}\right)^{T}$. Sementara Gain Derivative Observer dipilih $\mathrm{L}_{1}=0_{\text {nxp }}$ dan $\mathrm{L}_{2}=I_{p}$. Hasil estimasi noise pengukuran ditunjukkan pada Gambar 4. Untuk menguji kinerja modified $P D$ descriptor observer, diberikan nilai kesalahan pengukuran sesuai dengan karakteristik sensor posisi pada robot manipulator pada $t=20 \mathrm{~s}$ untuk kesalahan sensor pada joint pertama dan $t=30 \mathrm{~s}$ untuk kesalahan sensor pada joint kedua.

Lebih lanjut, estimasi kesalahan pengukuran pada robot manipulator 2-link dapat diamati dari residual pada Gambar 5. Nilai residual yang tidak sama dengan nol mengindikasikan terjadinya kesalahan pada sistem. Residual ini kemudian dievaluasi untuk membangkitkan sinyal alarm pada mekanisme isolasi kesalahan. Grafik isolasi kesalahan pada Gambar 6. menunjukkan fault alarm yang sesuai dengan kesalahan pengukuran yang diinputkan pada $t=50 \mathrm{~s}$ untuk kesalahan sensor pada joint pertama dan $t=100 \mathrm{~s}$ untuk kesalahan sensor pada joint kedua

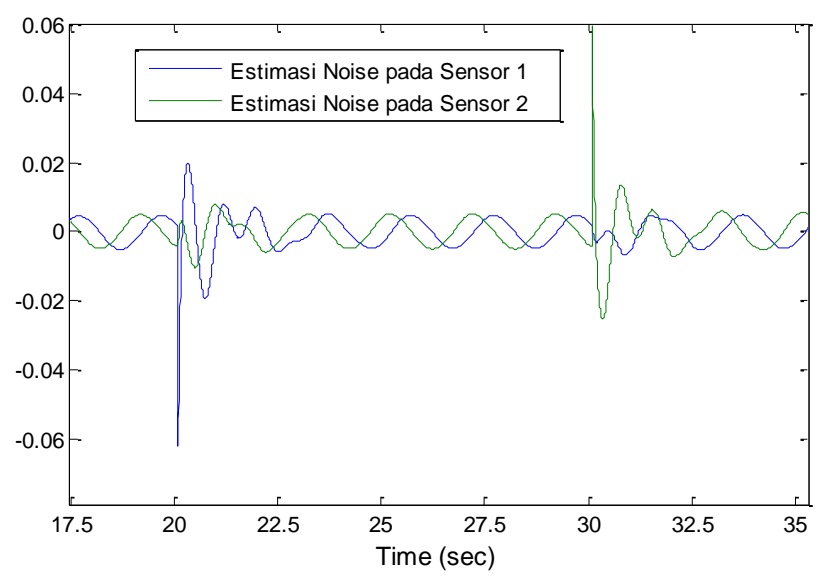

Gambar 4. Estimasi Noise menggunakan PD Descriptor Observer



Gambar 5. Residual pada $t=20 s$ dan $t=30 s$. 


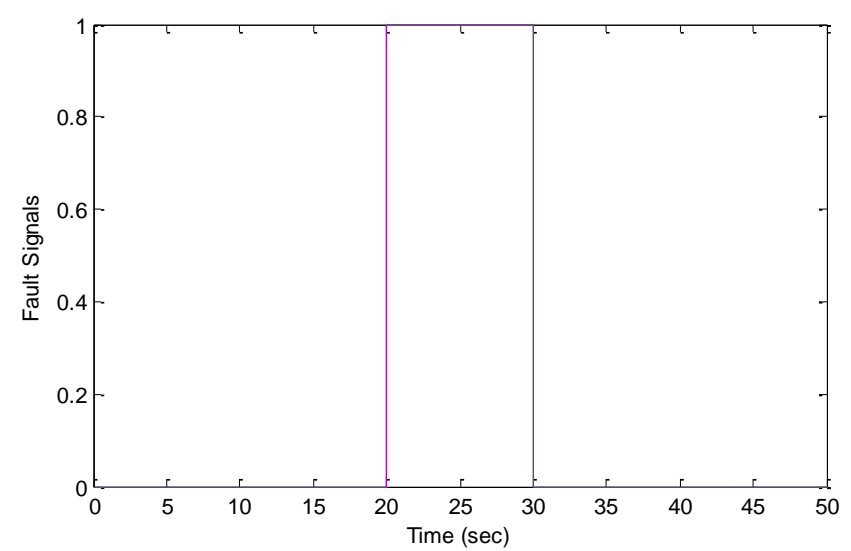

Gambar 6. Sinyal Isolasi Kesalahan pada $t=50 \mathrm{~s}$ dan $t=100 \mathrm{~s}$.

\section{KESIMPULAN}

Dengan menerapkan CTC pada robot manipulator, didapatkan sinyal kontrol umpan balik linier yang menjadi input bagi modified PD descriptor observer. Transformasi pemodelan robot manipulator ke dalam sistem augmented descriptor sehingga diperoleh formulasi desain observer yang baru yang mampu mengestimasi kesalahan pengukuran dan dapat diterapkan pada mekanisme FDI untuk memberikan sinyal alarm yang sesuai dengan sinyal kesalahan yang diinputkan pada pengukuran yang disimulasikan.

\section{DAFTAR PUSTAKA}

Alwi, H., 2011. Fault Detection and Fault Tolerant Control using Sliding Modes, Advances in Indutrial Control, Springer-Verlag London Limited.

Gao, Z., dan Wang, H., 2006. Descriptor observer approaches for multivariable system with measurement noises and application in fault detection and diagnosis, Science Direct, pp. 304313.
Lewis, F. L., Dawson, D. M., dan Abdallah C. T., 2006. Robot Manipulator Control Theory and Practice :Marcel Dekker New York.

Nie, C., 2012. Observer-Based Robust Fault Estimation For Fault-Tolerant Control, Dissertation, The University of Hull, Beijing.

Noura, H., Theilliol, D., Ponsart, J. C., dan Chamseddine, A., 2009. Fault Tolerant Control System, Springer-Verlag London Limited.

Piltan, F., Yarmahmoudi, M.H., Shamsodini, M., Mazlomian, E., dan Hosainpour, Ali., 2012. Puma-560 Robot Manipulator Position Computed Torque Control Methods Using MATLAB/SIMULINK and Their Integration into Graduate Nonlinear Control and MATLAB Course, International Journal and Automatio, Vol. 3, Issue, 3.

Zhang, K., 2011. Fault Detection and Diagnosis for A Multi Aktuator Pneumatic System, Dissertation Ph.D : Stony Brook University. 